\title{
Cushion plants as critical pioneers and engineers in alpine ecosystems across the Tibetan Plateau
}

\author{
Yi Wang ${ }^{1}$, Jian $\mathrm{Sun}^{2}$, Biying $\mathrm{Liu}^{1}$, Jinniu Wang ${ }^{3}$, and Tao Zeng ${ }^{4}$ \\ ${ }^{1}$ Sun Yat-Sen University \\ ${ }^{2}$ Institute of Tibetan Plateau Research Chinese Academy of Sciences \\ ${ }^{3}$ Chengdu Institute of Biology,Chinese Academy of Sciences \\ ${ }^{4}$ Chengdu University of Technology
}

May 14, 2021

\begin{abstract}
Cushion plants are widely representative species of the alpine ecosystem due to their vital roles in the abiotic and biotic environments, ecological succession processes, and ecosystem engineering. Importantly, Cushion plants, such as Androsace L. and Arenaria L., can be regarded as critical pioneers of ecosystem health, restoration and sustainability across the Tibetan Plateau because these plants (i) exhibit tenacious vitality, regulate regional climates, substrates and soil nutrients and keep warmth in extreme regions; (ii) facilitate relationships with surrounding and maintain the diversity of above- and below-ground communities; and (iii) have high sensitivity to environmental changes, which can indicate grassland ecosystem health and resilience in the context of global change.
\end{abstract}

\section{Cushion plants as critical pioneers and engineers in alpine ecosystems across the Tibetan Plateau}

Yi Wang ${ }^{1,2,3}$, Jian Sun ${ }^{2, *}$, Biying Liu ${ }^{2,3}$, Jinniu Wang ${ }^{4}$, Tao Zeng ${ }^{3, *}$

${ }^{1}$ School of Life Sciences and School of Ecology, State Key Lab of Biological Control, Sun Yat-sen University, Guangzhou, China.

2 State Key Laboratory of Tibetan Plateau Earth System Science (LATPES), Institute of Tibetan Plateau Research, Chinese Academy of Sciences, Beijing, China

${ }^{3}$ College of Earth Sciences, Chengdu University of Technology, Chengdu, 610059, China

4 Chengdu Institute of Biology, Chinese Academy of Sciences, Chengdu, China

*Corresponding authors. E-mail addresses: sunjian@itpcas.ac.cn (J. Sun), zengtao@cdut.cn (T. Zeng).

\section{Abstract}

Cushion plants are widely representative species of the alpine ecosystem due to their vital roles in the abiotic and biotic environments, ecological succession processes, and ecosystem engineering. Importantly, Cushion plants, such asAndrosace L. and Arenaria L., can be regarded as critical pioneers of ecosystem health, restoration and sustainability across the Tibetan Plateau because these plants (i) exhibit tenacious vitality, regulate regional climates, substrates and soil nutrients and keep warmth in extreme regions; (ii) facilitate relationships with surrounding and maintain the diversity of above- and below-ground communities; and (iii) have high sensitivity to environmental changes, which can indicate grassland ecosystem health and resilience in the context of global change. 
KEYWORDS: Cushion plants; Androsace L.;ArenariaL.; Tibetan Plateau; ecosystem succession.

\section{The cushion plant is a key builder of abiotic environments}

Cushion plants, with more than 70 kinds, are widely distributed in high elevations and inhabit extreme environments across the Tibetan Plateau (Badano \& Cavieres, 2006; Yang \& Sun, 2006). The Tibetan Plateau is an important centre of global cushion plants, e.g., Androsace L. andArenariaL., which play a vital role in the development of modern flora and vegetation (Luo et al., 2018). Firstly, the "microspace" formed by convex structure and developed root system of cushion plants could function in heat, nutrient and water preservation (Fig. 1a-c) (Cavieres et al., 2006; Zhao et al, 2020). Actually, these plants act as an ecological engineer to accelerate the enrichment of nutrients for the substrate, which can last for hundreds of years for tenacious vitality (Fig. 1d) (Yang et al., 2010). Second, the special structure and strong adaptability of cushion plants reduce the damage of wind and water erosion and maintain the warmth of extreme regions (Byers et al., 2006). Ultimately, dead cushion plants provide sufficient fertilizer for the soil and promote nutrient cycling.

Fig. 1 (a-c) The cushion plant, such as Androsace L., has the median uplifting structure to create "micro space" with developed root system; (f) The death cushion plant provides sufficient fertilizer for the surrounding plants.

\section{The cushion plant is a critical facilitator for biotic environments}

Cushion plants provide physical protection in extreme environments and promote the growth and reproduction of surrounding species, especially species of pioneer settlers (Cavieres et al., 2006; Francisco et al., 2020). Thus, cushion plants exhibit interspecific facilitation, which may be beneficial to maintain species diversity (Fig. 2) (Erfanzadeh et al., 2020). The main effects of cushion plants on the below-ground community are the promotion of the activity of soil microorganism and the enhancement fungal communities to increase the absorption area of roots and maintain microbial community diversity (Fig. 3) (Casanovakatny et al., 2011; Chang et al., 2018; Wang et al., 2020).

Fig. 2 The cushion plant promotes the propagation of other plants, such as Leontopodium, Carex and Artemisia .

Fig. 3 The cushion plant and fungi form symbionts to improve the activity of soil microbe.

\section{The cushion plant is an indicator of ecosystem health and resilience}

Cushion plants have high sensitivity to global change (e.g., climate, nitrogen deposition, species invasion and land use), such as their response to freezing-thawing and stress gradients, which may indicate ecosystem health and resilience (Gorsuch et al., 2001). Besides, cushion plants may be indicators of whether the ecosystem is healthy or degradation succession occurs (Erfanzadeh et al., 2020; Luo et al., 2018). Specifically, in the context of alpine grassland ecosystem degradation, the cushion plants play an important role in improving abiotic and biotic environments and the maintenance of alpine ecosystem stability (Fig. 4). 


\section{(a)}

(b)

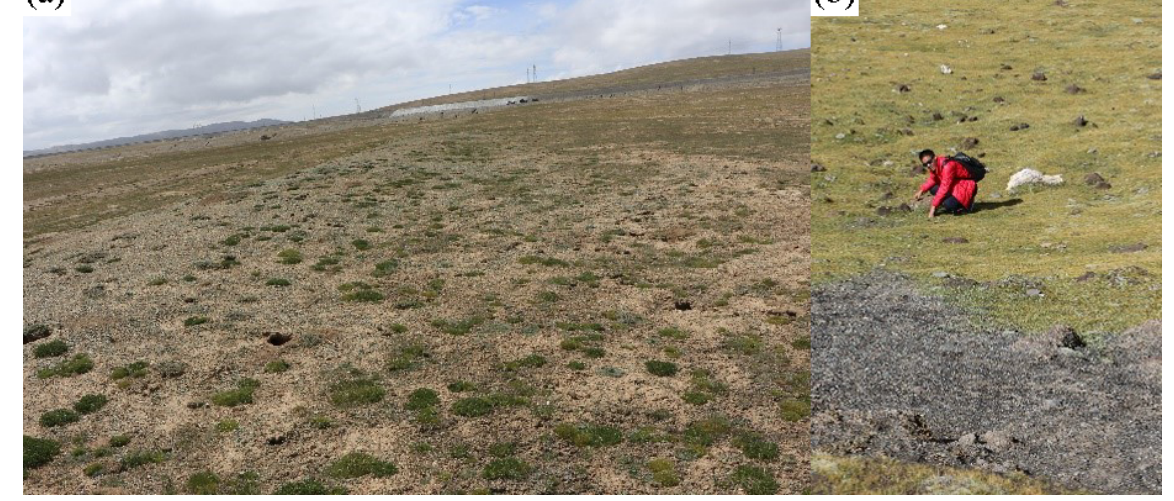

Fig. 4 Androsace L. andArenaria L. live in degraded grassland.

\section{Conclusions}

The cushion plant is a key species for the maintenance of the stability of the grassland ecosystem across the Tibetan Plateau. These plants are key builders of abiotic environments due to their vital roles in regional warmth maintenance, wind reduction and nutrient accumulation. These plants are also protectors of surrounding plants and show interspecific facilitation. Cushion plants promote species reproduction and are hotbeds for maintaining plant and microbial diversity. Notably, these plants are essential indicators of ecosystem health and sustainability and play an important role in the restoration of alpine grassland ecosystems under the influence of global change. Therefore, cushion plant appears to be both important pioneers and ecosystem engineers in alpine ecosystems of the Tibetan Plateau.

\section{Author Contributions}

YW and JS conceived the idea and study design, YW, JS and BL took photos and drafted the paper, JW and $\mathrm{TZ}$ revised the paper.

\section{Disclosure Statement}

The authors declare that they have no competing interests.

\section{Funding}

This study was supported by the Second Tibetan Plateau Scientific Expedition and Research Program [Grant No.2019QZKK0405].

\section{Data and Materials Availability}

All data needed to evaluate the conclusions in the paper are presented.

\section{References}

Badano, E. I., \& Cavieres, L. A. (2006). Impacts of ecosystem engineers on community attributes: effects of cushion plants at different elevations of the Chilean Andes. Diversity 85 Distributions , 12(4), 388-396. doi: 10.1111/j.1366-9516.2006.00248.x.

Byers, J. E., Cuddington, K., Jones, C. G., Talley, T. S., Hastings, A., Lambrinos, J. G., Crooks J. A., Wilson W. G. (2006). Using ecosystem engineers to restore ecological systems. Trends in Ecology and Evolution, 21(9), 493-500. doi: 10.1016/j.tree.2006.1006.1002.

Casanovakatny, M. A., Torresmellado, G., Palfner, G., Cavieres, L. A. (2011). The best for the guest: high Andean nurse cushions of Azorella madreporica enhance arbuscular mycorrhizal status in associated plant species. Mycorrhiza , 21(7), 613-622. doi: 10.1007/s00572-00011-00367-00571. 
Cavieres, L. A., Badano, E. I., Sierraalmeida, A., Gomezgonzalez, S., Molinamontenegro, M. A. (2006). Positive interactions between alpine plant species and the nurse cushion plant Laretia acaulis do not increase with elevation in the Andes of central Chile. New Phytologist, 169(1), 59-69. doi: 10.1111/j.14698137.2005.01573.x.

Chang, S., Chen, J., Su, J., Yang, Y., Sun, H. (2018). Seasonal comparison of bacterial communities in rhizosphere of alpine cushion plants in the Himalayan Hengduan Mountains. Plant Diversity , 40(05), 209-216. doi: 10.1016/j.pld.2018.1009.1003.

Erfanzadeh, R., Hazhir, S., Jafari, M. (2020). Effect of cushion plants on the soil seed bank in overgrazed semiarid regions. Land Degradation 83 Development , 31(8), 990-1000. doi: 10.1002/ldr.3517.

Francisco, I. P., Nuria, P., Petr, M., Christian, S., Carme, E., Cristina, A. (2020). Warming enhances growth but does not affect plant interactions in an alpine cushion species. Perspectives in Plant Ecology, Evolution and Systematics , 4, 125530. doi: 10.121016/j.ppees.122020.125530.

Gorsuch, D. M., Oberbauer, S. F., Fisher, J. B. (2001). Comparative vessel anatomy of arctic deciduous and evergreen dicots. American Journal of Botany , 88(9), 1643-1649. doi: 10.2307/3558409.

Luo, J., Liu, X., Yang, J., Liu, Y., Zhou, J. (2018). Variation in plant functional groups indicates land degradation on the Tibetan Plateau.Scientific reports 8(1), 17606. doi: 10.11038/s41598-17018-36028-17605.

Wang, C., Michalet, R., Liu, Z., Jiang, X., Wang, X., Zhang, G., An, L., Chen, S., Xiao, S. (2020). Disentangling large- and small-scale abiotic and biotic factors shaping soil microbial communities in an alpine cushion plant system. Frontiers in Microbiology , 11, 925. doi: 10.3389/fmicb.2020.00925.

Yang, Y., Niu, Y., Cavieres, L.A., Sun, H. (2010). Positive associations between the cushion plant Arenaria polytrichoides (Caryophyllaceae) and other alpine plant species increase with altitude in the SinoHimalayas.Journal of Vegetation Science, 21(6), 1048-1057. doi: 10.1111/j.1654-1103.2010.01215.x.

Yang, Y., Sun, H. (2006). Advances in the functional ecology of alpine and arctic plants. Acta Botanica Yunnanica , 28, 43-53. doi: 10.3969/j.issn.2095-0845.2006.3901.3010.

Zhao, R., Zhang, H., An, L. (2020). Spatial patterns and interspecific relationships of two dominant cushion plants at three elevations on the Kunlun Mountain, China. Environmental science and pollution research international , 27(14), 17339-17349. doi: 10.11007/s11356-17020-08324-z. 